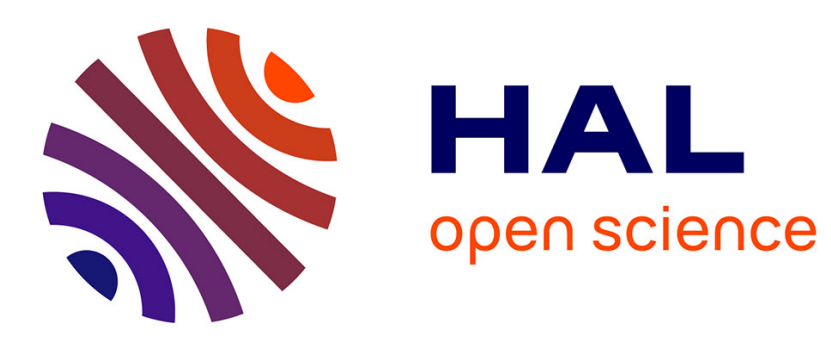

\title{
Reputation and Quality Indicators to improve Community Governance
}

Samer Hassan, Primavera de Filippi

\section{To cite this version:}

Samer Hassan, Primavera de Filippi. Reputation and Quality Indicators to improve Community Governance. Proceedings of Transvaluation Symposium, Chalmers University of Technology, May 2015, Gothenburg, Sweden. hal-01265197

\section{HAL Id: hal-01265197 \\ https://hal.science/hal-01265197}

Submitted on 31 Jan 2016

HAL is a multi-disciplinary open access archive for the deposit and dissemination of scientific research documents, whether they are published or not. The documents may come from teaching and research institutions in France or abroad, or from public or private research centers.
L'archive ouverte pluridisciplinaire HAL, est destinée au dépôt et à la diffusion de documents scientifiques de niveau recherche, publiés ou non, émanant des établissements d'enseignement et de recherche français ou étrangers, des laboratoires publics ou privés. 


\title{
Reputation and Quality Indicators to improve Community Governance
}

\author{
Samer Hassan \& Primavera De Filippi
}

\begin{abstract}
Social innovation presents new opportunities for participation and inclusion.Yet, many social innovation projects or initiatives are characterised by a power law distribution, where a large majority of contributions are provided by a very small portion of people. Besides, most of these initiatives lack a systematic structure and incentivization mechanism, but merely rely on irregular volunteer-driven participation. This not only impinges upon their long-term sustainability, but also significantly reduce their ability to scale over time.

Prior attempts at resolving these issues have been focusing for the most part on hierarchical structures or transaction-based models that mainly replicate traditional market logics. We propose here a new model of distributed governance for social innovation communities, based on a gratitude-based reward and reputation system that could promote inclusion and participation within these communities, without incurring the costs associated with centralized decision-making and without engaging into the distortive effects of today's market-based transactions.
\end{abstract}

\section{Keywords:}

reputation, reward systems, social innovation, community governance, participation, inclusion. 


\section{Introduction}

Burning Man (BM) is a community that gathers annually in the Black Rock Desert with the aim of artistic experimentation within a communal context. Mia and her "burner" friends enjoy contributing to different artistic projects.

Social Innovation (SI) are new ideas (products, services and models) that simultaneously meet social needs (more effectively than alternatives) and create new social relationships or collaborations (Murray et al 2010). We can catalogue as SI a wide range of phenomena (see Benkler, 2006), including popular ones such as free/libre/open source software (FLOSS) and Wikipedia, but also OpenStreetMap, Blablacar or Fablabs.

SI typically relies in communities which follow a "power law", or the 1-9-90 principle. This means that, approximately, the $1 \%$ of the community participants contribute very actively; the $9 \%$ contribute occasionally; and the $90 \%$ are more passive users of the content created. Different communities may have different percentages, and the same person may adopt different roles in different communities.

SI communities face multiple challenges that affect their sustainability:

- Participation is frequently volunteer-driven and irregular; e.g. strong contributors burnout, or casual contributors disappear because of different issues (Seifu \& Tsiavos, 2010).

- Large-scale governance is difficult: when the community is small, it is somehow easy to manage; however, the more the community grows, the more difficult consensus-building becomes (Bollier, 2014).

- There are barriers for participation, and the related economic/gender/origin gaps (e.g. low-income potential participants spend their time in market jobs that provide them income rather than in SI).

Although Mia loves BM, she is not able to participate every year: it requires plenty of free time, and depending on the moment that is simply not an option. Besides, her friend Layla simply cannot afford joining. For the BM community it is not easy either, as the community has grown to tens of thousands, governance has become more complicated.

There have been different attempts to reward contributions in order to facilitate participation and inclusion. However, many of them replicate the market logics (competitive, exchange), which are certainly different than the nature of SI (collaborative, sharing). For instance, crypto-currencies (e.g. Bitcoin) are typically based on a scarce resource which might disrupt SI dynamics.

Instead, and building upon our previous work (De Filippi \& Hassan, 2015), we propose a gratitude-based reputation system. Participants may express gratitude to each other for their work (i.e. gratitude as an immaterial reward for contributing), and each participant may have a 
reputation that is seen and understood by the rest. Reputation is a non-transferable asset (i.e. I cannot sell you a part of my reputation), and thus cannot promote exchange.

In the following pages, we will outline such gratitude-based rewards and reputation system, designed to promote inclusion and participation within SI communities. We hope it will facilitate participation and decentralized governance, and eventually also a transition towards a model in which the SI paradigm becomes mainstream.

\section{A reputation system for communities}

We propose an immaterial gratitude-based reward for community contributions. Any community member may express gratitude to another for a specific task or contribution she has performed. That is, anyone would feel appreciation for a contribution and its author(s), and express gratitude to her/them. Note this is different from simple liking of something/someone (as in Facebook's Like), which is a unidirectional binary relationship in which a person expresses abstract appreciation for an object. Instead, it is similar to other thanking mechanisms such as Hi.co (allowing people to leave a thank note to the author of appreciated articless) or Wikipedia (allowing people to submit a thanks to the author(s) of appreaciated contributions). The latter two examples constitute a unidirectional ternary relationship, in which a person directs gratitude to a person (as opposed to the object) because of an appreciated object,.

We can build, upon this simple method, value indicators for three emergent properties:

- Reputation for the contributors (i.e. the $1 \%$ and 9\%)

- Reputation for the users (i.e. mainly the $90 \%$, although also $1 \%$ and $9 \%$ )

- Quality for the contributions (the objects built or actions performed)

In order to build those indicators, we may use several algorithms. We propose to use an adaptation of Liao et al (2014), which can be simplified as follows:

- Contribution-based Reputation: Participants may thx other participant(s) for a specific contribution (or performed task), thus increasing their recognition within the community.

- Gratefulness-based Reputation: Participants also have a reputation based on the quality of the contributions they expressed gratitude for, i.e. if they express gratitude for contributions that are also recognized as high quality by the community they will have higher reputation than expressing gratitude "randomly".

- Contribution Quality: the emergent quality of a specific contribution increases with two factors: (1) the author(s) contribution-based reputation, i.e., the more acknowledged is the contribution author(s), the higher is considered the quality of the contribution; (2) the thx received by the contribution, not just depending on the simple number of thx, but also on who gives the thx (i.e. it is weighted by the gratefulness-based reputation of the participants that thx it: the more reputation has the participant, the more weight has its thx).

Mia has been working on an art piece and finally managed to change its form to fit into the

Ultimate Sculpt. Her friend Harald is grateful for her fantastic contribution to the common 
work. In fact, after Harald, many other "burners" express gratitude to Mia for this contribution. Thus, Mia's contribution-based reputation is sensibly increased, Harald's appreciation-based reputation is also increased, and the quality of this art piece is considered very high.
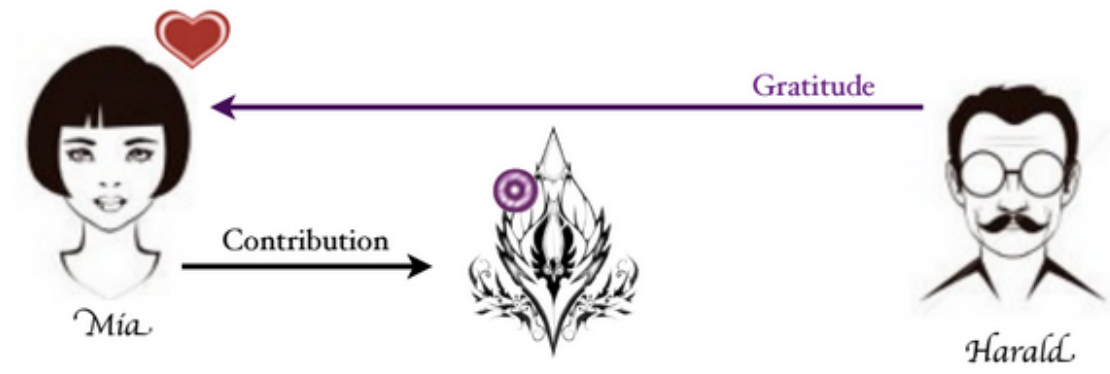

Harald

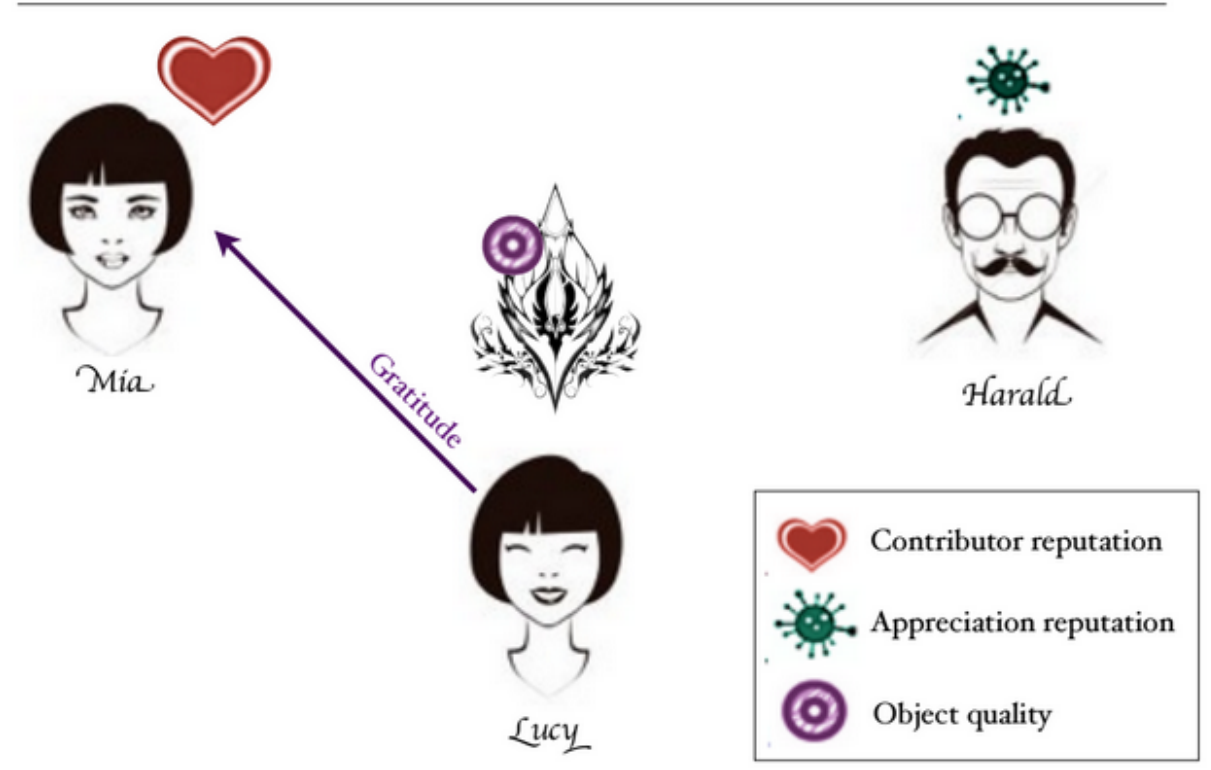

\section{In Practice: Possible Governance Models}

\section{Facilitating Coordination}

Coordination refers to the organization of the different elements of a given community or initiative, so as to enable them to work together effectively. Small-scale communities tend to self-manage appropriately, usually with a flat structure and rough-consensus governance. However, when communities progressively grow in size, they typically cannot be managed in the same way. Thus, scalability problems emerge: e.g. different levels of contribution and specialization of tasks require differentiation of roles; participants cannot be aware of all that is happening within the community, making it difficult and costly to ensure quality and compliance with internal rules. This 
is a traditional problem in human governance, which is commonly solved by more formality and structure, which often translates into hierarchical organizations.

SI communities are not an exception to these scalability issues. Thus, their most frequent form is a centralized hierarchical model in which the infrastructure owner (a company or institution) makes most of the decision-making (e.g. Flickr, Blablacar, Couchsurfing). In such models, the community is rather disempowered; besides, the benefits of the value created are frequently controlled by the owner.

There are other models implemented in different SI types, although they are less frequent. FLOSS projects are able to manage communities with thousands of contributors, through several levels of privileges (different roles and pseudo-meritocratic processes) and soft hierarchies (with no 'order and command', as volunteers cannot be forced to obey). Wikipedia has resolved the issue through representatives which are elected democratically (competing candidates and majority voting). Smaller communities aim to maintain a near-consensus flat organization, avoiding the scalability issue by not growing further and instead networking with other small nodes/communities (Indymedia nodes, grassroots wikis).

We provide here a solution that could potentially enable communities or initiatives to adopt a more organic model of coordination, even on a large scale. These new indicators allow for the deployment of novel governance systems that emerge organically through the systematic behavior of community members, on at least three different levels:

1. Decentralized alternative to filtering/prioritizing: The proposed system supports the process of distributed innovation within the community, allowing anyone to experiment with their own ideas and letting them grow. The object-quality indicator will eventually bring into light what are the most valuable projects or contributions in the eyes of the community as a whole. Community will thus be able to decide where to best focus their efforts.

Deciding which art projects to fund is a difficult task for the BM community. It can now be achieved in a decentralized manner: As artists start working on their projects, they can advertise the process onto the BM platform, for other burners to appreciate their work. BM might then observes the quality indicators at specific time intervals, in order to issue funds to the most appreciated projects.

2. Identification of skills: This system also enables new and dynamic governance models, where the gratefulness-based reputation can be used as an indicator of who are good at reflecting the value systems of a particular community, and the contribution-based reputation can help identify those who are skilled at different types of tasks. This may allow governance models in which thresholds of these indicators may be used to create specific task-forces or working groups with certain aims. 
Harald is an old burner, he has been attending the BM Festival for many years now, and he understands well the community's tastes and value system. Over the years, he has acquired a high gratefulness-based reputation, and his help is identified as valuable in one of the administrative working groups.

3. Better allocation of resources: More generally, the contribution-based reputation and object-quality indicators enable people to focus their efforts to where their contributions are the most valued, and/or to the project that have the highest value in the eyes of the community.

Lucy is a newcomer into the BM community. She wants to contribute, but doesn't know exactly where would her contribution be the most needed. Looking at the quality indicator. she can identify the projects which are the most appreciated by the community.

Conversely, Mia contributes to many different projects, but looking at her contribution-based reputation, she realizes that her contributions to one project are not really appreciated by the community. Mia thus decides to shift her efforts on another project, where her contributions are being much more appreciated.

\section{Incentivizing Participation}

In order to scale and to remain sustainable over time, communities need to achieve a constant (and growing) flow of contributors which are supporting the activities of the community. This system's indicators provide new ways for communities to assess the value of member's participation, with regard to:

- Contributing to the community (involving the 1\% and 9\%), with the contribution-based reputation illustrating how good of a contributor one is to the community;

- Assessing the value of others' contributions to the community (involving the $1 \%, 9 \%$ and $90 \%$ ), with the gratefulness-based reputation illustrating the extent to which one is able to properly assess the quality of a contribution, according to the specific value system of the community at stake.

Both reputation types should be kept distinct, to the extent that they communicate a different type of information. Yet, both can be used - either combined or by themselves- in order to build specific reward systems within a specific community. We illustrate here three possible models of rewards that could further incentivize participation into any given community.

1. Tokens: Some communities may need a more standard exchange system rather than the non-transferable reputation proposed here. In that case, they may want to distribute tokens based on the reputation accumulated by its members (both in terms of contribution-based reputation and gratefulness-based reputation), which - as opposed to the reputation itselfare both transferable and consumable. These tokens may have different uses agreed by the community. For instance, they could be used to purchase certain goods (e.g. to purchase tickets) or to benefit from the services offered by the community (e.g. get free rides). The 
community may allow them to be sold on the market, to non-community members that want to purchase these goods or services.

Mia is a great contributor to the BM community. BM gives her tokens to reward her participation into the community, according to both her contribution-based reputation and her gratefulness-based reputation. Mia can either use these tokens in order to purchase Burning Man's tickets, or can sell the tokens to third parties, who might be interested in purchasing these tickets.

2. Roles \& Privileges: The community can use contribution- and/or gratefulness-based reputation in order to grant certain privileges to those who participated the most, or whose contributions were the most valuable to the community (e.g. good appreciators can be upgraded into administrators, good contributors can enjoy higher weight concerning the community practical decisions, etc).

BM needs to deal with a scarcity of tickets, as more people want to attend the festival than is effectively possible. Rather than selling tickets on a first-come-first-served basis, there is now a way to discriminate amongst people, e.g. favoring those who contributed to the BM community (or to other like-minded communities).

Because of her high reputation, Mia is given priority when it comes to purchasing the ticket. Thus, she can secure her spot into the festival, before the tickets are actually sold to the public.

3. External rewards: Third-parties - be they communities, public actors, or market actorsthat share a similar value system with the community might recognize the value expressed by this system's indicators and reward contributors accordingly (e.g. providing discounted products or free services to the community members with higher contribution- or gratefulness-based reputation).

There are many local BM communities, or other like-minded initiatives around the world that share similar value systems as BM. These communities recognize Mia's value for contributing to BM, and give her special gifts (e.g. discounted tickets or free drinks).

\section{Improving inclusion}

Although, in principle, participation is typically open to anyone, SI has strong barriers for participation (Carillo, 2008). Let's pick Wikipedia as an example: Who can contribute to it? Anyone who wants to, or only those who actually can? The most common profile is someone knowledgeable about technology, with a lot of free time and who can afford investing time and effort in non-remunerated work. This limits the participation of those who need to take care of family or children, those with several jobs, or who are swallowed by debts, etc. Besides, most 
communities have a deep gender gap, with a male majority that may trigger uncomfortable dynamics for many women (e.g. aggressive discussions, high individual visibility).

We believe our gratitude-based reward system will incentivise participation and, furthermore, make such participation more inclusive. There is evidence that, contrary to other types of rewards, gratitude-based rewards are appreciated by female collaborators, who, in fact, tend to express gratitude more frequently (Iosub et al 2014, Fuster Morell 2010).

Moreover, if external rewards (see previous section) were to spread, contributing to SI communities could be potentially rewarded with tangible resources (i.e. goods or services, and not just immaterial tokens or reputation). This would strongly facilitate participation of those with disadvantaged circumstances (e.g. low-income, sole-parents), who could progressively shift towards contributing more and more to SI, while becoming less dependant on the Market or State. Thus, we hope this system would make contributing to SI SI more inclusive and sustainable for those who cannot typically afford to participate.

Before, Layla was not able to participate in BM. However, since they adopted the new gratitude-based rewards, it is much easier for her to do, helped by her friend Mia. Mia paid her the expensive BM ticket, and Layla can now use her amazing talent in multiple BM projects. As she is found strongly valuable by the community, she is rewarded with BM tokens... that she can use to pay back Mia.

\section{Conclusion}

The proposed system may raise multiple doubts and uncertainties. We may be able to answer some of them (as here we are constrained to the limited space), but obviously not all. We are tackling very complex issues, and their implementation in practice may be tricky and complicated. Still, we believe this is a fascinating set of questions, and we propose this system as starting point for discussion. We hope this may be the seed of a new wave of community rewards that may push the SI paradigm into the mainstream. 


\section{Acknowledgements}

We would like to acknowledge the P2Pvalue members for their insights. This work was partially supported by the Framework programme FP7-ICT-2013-10 of the European Commission through project P2Pvalue (grant no.: 610961).

\section{License}

This article and its images are released under Creative Commons Attribution 4.0 International (CC BY 4.0). The full text of the license can be found in https://creativecommons.org/licenses/by/4.0/

\section{References}

- Benkler, Y. (2006). The wealth of networks: How social production transforms markets and freedom. Yale University Press.

- Bollier, D. (2014). The Commons as a Template for Transformation.

- Carrillo, F. J. (2008). Towards a global knowledge-based development agenda.Journal of Knowledge Management, 12(5), 3-7.

- De Filippi, P., Hassan, S. "Measuring Value in Commons-based Ecosystem: bridging the gap between the Commons and the Market", in Lovink G., Tkacz N. (eds), MoneyLab Reader, INC Reader (9):74-91. Institute of Network Cultures, University of Warwick.

- Fuster Morell, M. (2010). Governance of online creation communities: Provision of infrastructure for the building of digital commons. European University Institute.

- Iosub, D., Laniado, D., Castillo, C., Morell, M. F., \& Kaltenbrunner, A. (2014). Emotions under discussion: Gender, status and communication in online collaboration. Plos one, 9(8), e104880.

- Liao, H., Xiao, R., Cimini, G., \& Medo, M. (2014). Network-Driven Reputation in Online Scientific Communities. PloS one, 9(12), e112022.

- Murray, R., Caulier-Grice, J., \& Mulgan, G. (2010). The open book of social innovation. National Endowment for Science, Technology and the Art.

- Seifu, Z., \& Tsiavos, P. (2010). To Rule and Be Ruled: Governance and Participation in FOSS Projects. In Open Source Software: New Horizons (pp. 380-388). Springer Berlin Heidelberg. 